\title{
Metabolic Syndrome in Bangladeshi Menopausal Women
}

\author{
MS JAHAN ${ }^{\mathrm{a}}$, SMB BILLAH ${ }^{\mathrm{b}}$
}

Summary:

Objective: To assess the factors of metabolic syndrome (MetS)

in post menopausal women in Bangladesh.

Methods: Menopausal women are at increased risk of metabolic syndrome (MetS). This cross-sectional study on 64 willing post menopausal women from an urban and a rural area of Bangladesh was done. The socio-epidemiologic factors with anthropometric examination, blood pressure recording and fasting blood analysis for triglyceride (TG), high density lipoprotein (HDL), sugar were studied.

Results: Prevalence of MetS was 50.0\% (95\% CI= 39.9\%$60.1 \%$ ) among menopausal women, seventy five percent of them were urban. Low HDL cholesterol prevailed in almost 96\% respondents followed by high TG (51\%), obesity (28.0\%), high fasting blood sugar (FBS, 27.1\%) and hypertension (HTN, 16.9\%). On logistic regression, age

\section{Introduction:}

Menopause is the inevitable event terminating reproductive segment of women's life. Worldwide life expectancy has increased and as a result increasingly more women are now passing a longer period of their life after menopause. The post menopausal life is being associated with an increased risk ${ }^{1}$ of metabolic syndrome (MetS) that had been recognized as a public health problem ${ }^{2}$. Defined by different expert bodies ${ }^{3-6}$, the criteria of MetS by the Adult Treatment Panel III ${ }^{4}$ (ATP III) of National Cholesterol Education Program (NCEP) had been widely used. The ATP III criteria defines MetS as the presence of 3 of 5 factors namely a) abdominal obesity, determined by waist circumference $\geq 88 \mathrm{~cm}$ ( $35 \mathrm{inch}$ ) in women, $\geq 102 \mathrm{~cm}$ (40 inch) in men, b) high Triglyceride (TG) $\geq 1.7 \mathrm{mmol} / \mathrm{l}(150 \mathrm{mg} / \mathrm{dl}$ ), c) low High Density Lipoprotein (HDL) cholesterol $<1.3 \mathrm{mmol} /$

a. Dr. Muna Shalima Jahan, Associate Professor, Department of Obstetrics \& Gynaecology, Sir Salimullah Medical College, Dhaka

b. Dr. Syed Muhammad Baqui Billah, Department of Community Medicine, Sher-e Bangla Medical College, Barisal

Address of Correspondence: Muna Shalima Jahan, Associate Professor, Department of Obstetrics \& Gynaecology, Sir Salimullah Medical College, Dhaka - 1000, Telephone: +8801711-110090, Email: shalimajm@gmail.com

Received: 10 June, 2014 Accepted: 15 September, 2015
(OR=1.6, 95\% CI: 1.3-1. 9), male sex $(O R=2.5,95 \%$ CI: 1.4-4.2) and exercise (OR=1.9, 95\% CI: 1.2-2.9) produced significantly higher odds of being associated with MetS; rural area $(O R=1.4,95 \% C I: 1.0-2.1)$ and sedentary occupation (OR=1.7, 95\% CI: 0.9-3.0) were associated just insignificantly. Though higher income, better education, good physical movement and knowledge of MetS produced protective odds, they were not significant.

Conclusions: The study suggests that MetS is highly prevalent among Bangladeshi menopausal women. Further studies are needed to identify risk factors and for effective preventive measures to control this metabolic disease.

Key Words: Metabolic Syndrome, Epidemiology, Obesity, Lifestyle, Bangladesh

(J Banagladesh Coll Phys Surg 2016; 34: 15-20)

l ( $50 \mathrm{mg} / \mathrm{dl})$ in women, $<1.03 \mathrm{mmol} / \mathrm{l}(40 \mathrm{mg} / \mathrm{dl})$ in men, d) high Blood Pressure (BP) $\geq 134 / 85$ mm Hg, e) high Fasting Blood Sugar (FBS) $\geq 6.1 \mathrm{mmol} / \mathrm{l}(110 \mathrm{mg} / \mathrm{dl})$. The problem of MetS has been shown a steady increase in all populations with a propensity towards older age $\mathrm{e}^{7-11}$ associating with lifestyle, diet, body mass, risky behaviour, abdominal obesity, insulin resistance glucose metabolism, dyslipidemia, increased blood pressure and even non-alcoholic fatty liver.

Of the factors, weight gain had been identified ${ }^{12-13}$ to be associated with MetS in menopausal women with increasing risk of cardiovascular disease ${ }^{14}$ (CVD) and acquiring all of its components ${ }^{15}$. As experienced by the Asians ${ }^{16-20}$, Bangladesh ${ }^{21,22}$ also have similar experience on MetS although there are scopes to assess the situation in menopausal women in a community. Identifying the community risk for MetS in menopausal women could be an important research work to reject the primary null hypothesis that there was no difference of MetS factors in menopausal women in Bangladesh.

\section{Materials and Methods:}

The cross sectional study was conducted on 490 willing respondents, 275 of whom were females using Power and Sample Size program software ${ }^{23}$ to include a representative sample from one urban and a rural area. The data collection was done after getting ethical 
clearance from Bangladesh Medical Research Council (BMRC) in 2010. Out of total female population, there were 64 post menopausal women on which the secondary analysis of data was done. Respondents' socio demographic and behavioural information was recorded followed by anthropometric and blood pressure (BP) was measurement. Fasting blood was taken for the measurement of TG, HDL and FBS.

Necessary editing and coding of the data was done before final analysis accordingly $24,25,26$. All the components of metabolic syndrome were categorised by threshold value according to ATP III criteria and MetS was calculated with all possible combination of components together. Collating all the MetS components, dichotomous variable was created as either having MetS or not. The number of combination of components was added for total number of combined components distributed within the respondents.

Univariate analysis of the basic socio-demographic and suspected factors was done using $\mathrm{c}^{2}$ test for categorical data and Mann-Whitney $U$ test for continuous data. The data were presented as proportion and mean \pm SD respectively. For variable selection of independent effect measurement in logistic regression, the researcher followed the rule $e^{27,28}$ of minimum number of event or non-event divided by 15 (10-20), i.e. number of variable inclusion for adjustment of confounding factors. As there were 32 respondents in no MetS and 32 in MetS group, so both were same, and dividing the number by
10 , it was found that the researcher could include a maximum of 4 variables in the equation. Logistic regression was also done for looking at the interaction by discrete interaction model assessment with the significant variables found in univariate analysis. After initial regression, the non-significant variables were removed to look for best fit model in a stepwise fashion. Confidence Interval Analysis (CIA) software was used to calculate the $95 \%$ confidence interval (CI) for the prevalence of MetS and its components. Ap value d”0.05 was considered statistically significant. The near significant variables with a $\mathrm{p}$ value d"0.1 were also quoted with caution.

\section{Results:}

The prevalence of MetS was 50.0\% (95\% CI= 39.9\%$60.1 \%$ ) in the study. Low HDL prevalence was highest (96.9\%, 95\% CI=91.0-99.0) among the components of MetS followed by TG (51.6\% 95\% CI= 41.4-61.6), DM (40.6\%, 95\% CI= 31.1-50.9), HTN (32.8\%, 95\% CI= 24.0$43.0)$ and obesity $(10.9 \%, 95 \% \mathrm{CI}=6.0-19.0)$. Of the combined components high TG, low HDL and DM concluded a quarter of respondents followed by high TG low HDL and HTN (18.8\%). Nearly 11\% of the respondents had combination of four components as obesity, high TG, low HDL and DM while another 9.4\% had combination of HTN, high TG, low HDL and DM. Table 1 shows the prevalence of components of metabolic syndrome with 95\% CI.

Table-I

\begin{tabular}{|c|c|c|}
\hline \multicolumn{3}{|c|}{ Prevalence of components of MetS } \\
\hline Components (\%) & $\mathrm{N}(\%)$ & $95 \%$ CI of $\%$ \\
\hline Obese & $7(10.9)$ & $6.0-19.0$ \\
\hline $\mathrm{HTN}$ & $21(32.8)$ & $24.0-43.0$ \\
\hline$-\mathrm{TG}$ & $33(51.6)$ & 41.4-61.6 \\
\hline${ }^{-} \mathrm{HDL}$ & $62(96.9)$ & $91.0-99.0$ \\
\hline DM & $26(40.6)$ & 31.1-50.9 \\
\hline$-\mathrm{TG}+{ }^{-} \mathrm{HDL}+\mathrm{DM}$ & $16(25.0)$ & $17.2-34.8$ \\
\hline$-\mathrm{TG}+{ }^{-} \mathrm{HDL}+\mathrm{HTN}$ & $12(18.8)$ & $12.0-28.0$ \\
\hline $\mathrm{DM}+{ }^{-} \mathrm{HDL}+\mathrm{HTN}$ & $11(17.2)$ & $10.8-26.3$ \\
\hline$-\mathrm{TG}+\mathrm{HTN}+\mathrm{DM}$ & $6(9.4)$ & 4.9-17.1 \\
\hline Obese $+{ }^{-}$HDL + DM & $4(6.3)$ & 2.8-13.2 \\
\hline Obese $+-\mathrm{TG}^{+}{ }^{-} \mathrm{HDL}$ & $3(4.7)$ & 1.9-11.2 \\
\hline Obese+-TG+ HDL+DM & $7(10.9)$ & $6.0-19.0$ \\
\hline $\mathrm{HTN}+-\mathrm{TG}^{+}{ }^{-} \mathrm{HDL}+\mathrm{DM}$ & $6(9.4)$ & 4.9-17.1 \\
\hline
\end{tabular}


One interesting feature was observed with the non modifiable risk factor, the age. Figure 1 depicts the preponderance of MetS with advancing age though the association of higher age and MetS has not been statistically significant $\left(c^{2}=4.13, p=0.25\right)$.

None of the respondents had any knowledge of the term MetS. The socio-demographic and other variables are shown in Table 2. None of age, education, occupation or area of residence was associated with MetS. Though MetS respondents had higher average income than no MetS respondents, it was not significant. Water intake and sleeping duration were also not associated. Height was not related with MetS though MetS respondents were nearly six kg heavier $(\mathrm{p}=0.05)$ than no MetS respondents as reflected by significantly higher BMI ( $\mathrm{p}=0.05)$. While looking at the components, MetS respondents had high waist circumference $(\mathrm{p}=0.03)$, high SBP $(\mathrm{p}<0.001)$, high DBP $((\mathrm{p}<0.001)$, high TG $(\mathrm{p}<0.001)$, high FBS $(\mathrm{p}<0.001$. The MetS respondents had lower HDL than no MetS respondents, but the difference just missed the significance level ( $\mathrm{p}=0.09$ ).

The significant factors were put into stepwise logistic regression model to check the magnitude of association with MetS added with age. These are shown in Table 3, where DBP (OR=1.24, 95\% CI= 1.081.41), TG (OR=1.03, 95\% CI=1.01-1.05), obesity $(\mathrm{OR}=1.12,95 \% \mathrm{CI}=1.01-1.25)$ and $\mathrm{DM}(\mathrm{OR}=1.02,95 \%$ $\mathrm{CI}=1.00-1.04$ ) became significant predictor of MetS in the final model.

Table-II

\begin{tabular}{|c|c|c|c|}
\hline \multicolumn{4}{|c|}{ Baseline characteristics $^{1}$ of MetS respondents according to ATP III } \\
\hline Variables $^{2}$ & No $(n=32)$ mean \pm SD & Yes $(n=32)$ mean \pm SD & $\mathrm{p}^{3}$ \\
\hline Age (years) & $52.03 \pm 9.19$ & $51.38 \pm 8.12$ & 0.96 \\
\hline Income (/month) & $32.97 \pm 62.972637 .50 \pm 5037.52$ & $121.48 \pm 443.199718 .75 \pm 35454.86$ & 0.94 \\
\hline Water intake(lit/day) & $3.45 \pm 1.73$ & $2.94 \pm 1.31$ & 0.34 \\
\hline Sleep & $6.33 \pm 2.12$ & $6.30 \pm 1.92$ & 0.67 \\
\hline Weight (kg) & $53.83 \pm 10.49$ & $59.63 \pm 12.20$ & 0.05 \\
\hline Height (cm) & $153.63 \pm 6.06$ & $153.94 \pm 5.92$ & 0.89 \\
\hline $\operatorname{BMI}\left(\mathrm{kg} / \mathrm{m}^{2}\right)$ & $22.78 \pm 4.14$ & $25.06 \pm 4.48$ & 0.05 \\
\hline Waist (cm) & $86.84 \pm 8.80$ & $93.97 \pm 13.65$ & 0.03 \\
\hline SBP (mm Hg) & $125.44 \pm 15.01$ & $144.06 \pm 14.53$ & $<0.001$ \\
\hline DBP (mm Hg) & $75.94 \pm 11.42$ & $86.81 \pm 9.53$ & $<0.001$ \\
\hline TG (mg/dl) & $137.28 \pm 69.36$ & $214.47 \pm 101.25$ & $<0.001$ \\
\hline HDL (mg/dl) & $37.31 \pm 6.84$ & $34.59 \pm 5.51$ & 0.09 \\
\hline FBS (mg/dl) & $101.66 \pm 44.69$ & $151.91 \pm 74.80$ & $<0.001$ \\
\hline Area & & & 0.11 \\
\hline Urban & 18(42.9) & $24(57.1)$ & \\
\hline Rural & $14(63.3)$ & $8(36.4)$ & \\
\hline Education & & & 0.96 \\
\hline Illiterate & $9(47.4)$ & $10(52.6)$ & \\
\hline Some Education & $18(51.4)$ & $17(48.6)$ & \\
\hline Good Education & $5(50.0)$ & $5(50.0)$ & \\
\hline Occupation & & & 0.77 \\
\hline Sedentary & $8(47.1)$ & $9(52.9)$ & \\
\hline Heavy & $24(51.1)$ & $23(48.9)$ & \\
\hline
\end{tabular}

${ }^{1}$ Continuous values were presented in means and standard deviations (SD), categorical values in frequencies and proportions.

${ }^{2}$ Age/age group in years, monthly income in USD converted from Bangladesh Taka (BDT: 1 BDT=1/80USD), water intake in litre/ day, sleep in hours of sleep/day, weight in kilogram, height in $\mathrm{cm}$.

${ }^{3}$ Mann-Whitney U test were done for continuous variables while $c^{2}$ or Fisher's exact test was applied for categorical variables. 
Table-III

Stepwise logistic regression with suspected factors related to MetS

\begin{tabular}{|c|c|c|c|c|}
\hline \multirow[t]{2}{*}{ Initial model } & \multirow[t]{2}{*}{ OR } & \multicolumn{2}{|c|}{$95 \%$ CI for OR } & \multirow[t]{2}{*}{$\mathrm{p}$} \\
\hline & & Lower & Upper & \\
\hline Age & 1.01 & 0.90 & 1.13 & 0.91 \\
\hline SBP & 1.04 & .97 & 1.12 & 0.29 \\
\hline DBP & 1.20 & 1.04 & 1.396 & 0.02 \\
\hline Obesity & 1.13 & 1.00 & 1.271 & 0.05 \\
\hline DM & 1.02 & 0.99 & 1.05 & 0.06 \\
\hline$-\mathrm{TG}$ & 1.02 & 1.00 & 1.04 & 0.02 \\
\hline HDL & 0.98 & 0.81 & 1.19 & 0.85 \\
\hline \multirow[t]{2}{*}{ Final model } & $\mathrm{OR}$ & \multicolumn{2}{|c|}{$95 \%$ CI for OR } & $\mathrm{p}$ \\
\hline & & Lower & Upper & \\
\hline $\mathrm{DBP}$ & 1.24 & 1.08 & 1.41 & 0.002 \\
\hline Obesity & 1.12 & 1.01 & 1.25 & 0.04 \\
\hline DM & 1.02 & 1.00 & 1.04 & 0.045 \\
\hline$-\mathrm{TG}$ & 1.03 & 1.01 & 1.05 & 0.005 \\
\hline
\end{tabular}

Non metabolic syndrome

Metabolic syndrome

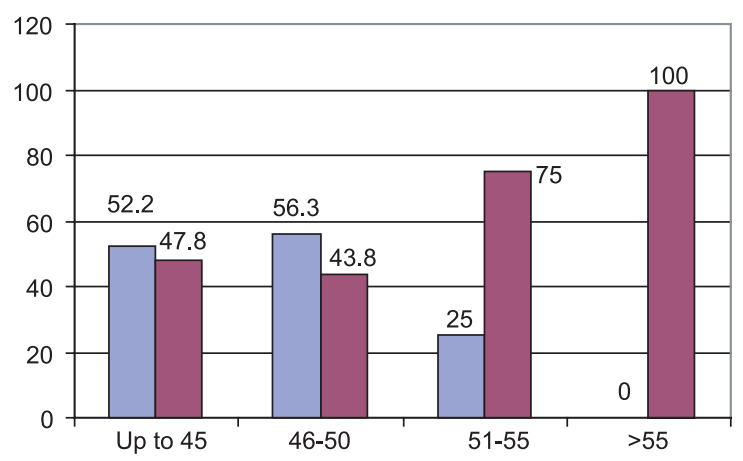

Fig.-1: MetS at different ages

\section{Discussion:}

The prevalence of MetS in this study population was $50 \%$ and was largely determined by obesity, high diastolic blood pressure high TG and diabetic status. The finding was similar to other studies ${ }^{15,29}$. Shihua $\mathrm{F}$ et al in china ${ }^{30}$ and Heideri $\mathrm{R}$ et al in $\operatorname{Iran}^{31}$ also found hypertension and high TG to be associated with Mets. Jouyandeh et al ${ }^{1}$ didn't find any difference of age in their study but they found all the components of MetS were significantly different from those of without MetS. Mahajan $\mathrm{N}$ et $\mathrm{al}^{33}$ showed the proportion of HTN and DM in menopausal women increases after 50 years of age. The current study also conform similarity to the study of Jouyandeh and Mahajan though the association was not statistically significant. Had the sample size been larger this association would become significant. Carr $\mathrm{MC}^{34}$ in her review article discussed that the prevalence of MetS increases with menopause having the risk of suffering from cardio vascular disease (CVD), increase TG levels, reduced HDL and increased glucose levels. Though she expressed of the unclear idea whether the transition of menopause increases the CVD risk in all women or only those who become the candidate of MetS. Lee JS ${ }^{35}$ did not find any independent association of HTN or DM with menopause but they found only hypercholesterolemia was associated with menopause.

The study had several limitations. Firstly, the sampling was done from only one urban and one rural area. So it would be hard to ascertain whether the studied prevalence of MetS was an underestimate or overestimate of the true prevalence. Detailed information on lifestyle and eating pattern was not done hence it was not possible to assess the type of food or lifestyle as predictive factors. But as the study assessed both rural and urban population, it can be considered the community-based study in Bangladesh to know the preliminary situation. A well documented protocol for easy diagnosis, management and prevention could be 
worked out by the policy makers using this baseline data to manage the syndrome accordingly.

\section{References:}

1. Jouyandeh Z, Nayebzadeh F, Qorbani M, Asadi M. Metabolic syndrome and menopause. Journal of Diabetes \& Metabolic Disorders. In BioMed Central, 2013; 12: 1-4.

2. Watanabe T, Murata C, Watanabe Y. The Metabolic Syndrome from the View Point of Public Health: With Special Reference to Nonalcoholic Fatty Liver Disease. Japanese Journal of Public Health, 2005; 52 (11):934-942.

3. World Health Organization. Definition, diagnosis and classification of diabetes mellitus and its complications. In: Report of a WHO consultation 1999; WHO, Geneva.

4. Grundy SM, Cleeman JI, Daniel SR, Donato KA, Eckel $\mathrm{RH}$, Franklin BA et al. Diagnosis and Management of the Metabolic Syndrome. An American Health Association/ National Heart, Lung, and Blood Institute Scientific Statement. Circulation 2005; 112: 2735-2752.

5. International Diabetes Federation. The IDF consensus worldwide definition of the metabolic syndrome. Available in http//www.idf.org/webdata/docs/MetS_def_update 2006.pdf.

6. Alberti KG, Zimmet P, Shaw J. Metabolic Syndrome-a new world-wide definition. A Consensus Statement from the International Diabetes Federation. Diabet Med 2006; 23: 469-480.

7. Procopiou M, Philippe J. The metabolic syndrome and type 2 diabetes: Epidemiological figures and country specifications. Cerebrovasc Dis 2005; 20 (suppl 1): 2-8.

8. Latre ML, Andres EM, Cordero A, Pascual I, Vispe C, Laclaustra $\mathrm{M}$ et al. Relationship between metabolic syndrome and ischemic heart disease mortality in Spain. Rev Esp Cardiol 2009; 62 (12): 1469-1472.

9. Ford ES, Giles WH, Dietz WH. Prevalence of the metabolic syndrome among us adults: findings from the third national health and nutrition examination survey. JAMA 2002; 287: 356-359.

10. Sharifi F, Mousavinasab SN, Saeini M, Dinmohammadi M. Prevalence of metabolic syndrome in an adult urban population of west of Iran. Experimental Diabetes Research 2009: 1-5.

11. Lee W-Y, Park J-S, Noh S-Y, Rhee EJ, Kim SW, Zimmet PZ. Prevalence of metabolic syndrome among 40698 Korean metropolitan subjects. Diabetes Research and Clinical Practice 2004; 65: 143-149. Global Health Action 2009; 44-53.

12. Arthur FKN, Adu-Frimpong M, Osei-Yeboah J, Mensah FO, Owusu L. The prevalence of metabolic syndrome and its predominant components among pre-and postmenopausal Ghanaian women. BMC Research Notes 2013; 6: 446-457.
13. KIM HM, Ryu SY, Park J, Kim J. The Effect of Menopause on the Metabolic Syndrome among Korean Women. Diabetes Care 2007; 30:701-706.

14. Isomaa B et al. Cardiovascular Morbidity and Mortality Associated with Metabolic Syndrome. Diabetes Care 2001; 24: 683-689.

15. Lobo AR. Metabolic syndrome after menopause and the role of hormones. The European Menopause Journal (Mauritas), 2008; 60: 10-18.

16. Higashiyama A, Okamura T, Ono Y, Watanabe M, Kokubo Y, Okayama A. Risk of smoking and metabolic syndrome for incidence of cardiovascular disease- comparison of relative contribution in urban Japanese population: The Suita Study. Circ J 2009; 73: 2258-2263.

17. Eapen D, Kalra GL, Merchant N, Arora A, Khan BV. Metabolic syndrome and cardiovascular disease in South Asians. Vascular Health and Risk Management 2009; 5: 731-743.

18. Misra A. Overnutrition and nutritional deficiency contribute to metabolic syndrome and atherosclerosis in Asian Indians. Nutrition 2002; 18: 702-703.

19. Kim HM, Ryu SY, Park J, Kim J. The effect of Menopause on the Metabolic Syndrome among Korean Women. Diabetes Care, 2007; 30: 701-706.

20. Ramachandran A, Snehalata C, Satyavani K, Sivasankari S, Vijay V. Metabolic syndrome in urban Asian Indian adultsa population study using modified ATP III criteria. Diabetes Research and Clinical Practice 2003; 60: 199-204.

21. Zaman MM, Ahmed J, Choudhury SR, Sharkar MN, Islam MS, Parvin K. Prevalence of metabolic syndrome in rural Bangladeshi women. Diabetes care. 2006; 29 (6): 1456-1457.

22. Siddique MA, Sultan MAU, Haque KMHSS, Zaman MM, Ahmed CM, Rahim MA et al. Clustering of metabolic factors among the patients with essential hypertension. Bangladesh Med Res Counc Bull. 2008; 34: 71-75.

23. Dupont WD, Plummer WD: "Power and Sample Size Calculations: A Review and Computer Program", Controlled Clinical Trials 1990; 11:116-28.

24. Coinmill.com - The Currency Converter. Bangladeshi Taka (BDT) and USD currency exchange rate conversion calculator. Available from: http://coinmill.com/ BDT_USD.html\#USD=1

25. Asian Development Bank. Purchasing power parity. Preliminary report. In: 2005 International Comparison Program in Asia and the Pacific. Asian Development Bank. Philippines. 2005.

26. World Bank. 2004 Annual review of development effectiveness: The World Bank's contributions to poverty reduction. World Bank. Washington DC. USA. 2005. 
27. Peduzi P et al. A simulation study on the number of events per variable in logistic regression analysis. J Clin Epidemiol. 1996; 49 (12): 1373-1379.

28. Harrell Jr. Frank E. In: Harrell Jr. Frank E. Regression modeling strategies: with application to linear models, logistic regression, and survival analysis. Springer Verlag New York Inc: Springer, 2001.

29. Shidfar F, Alborzi F, Salehi M, Nonomi M. Association of waist circumference, body mass index and conicity index with cardiovascular risk factors in postmenopausal women. Cardiovascular Journal of Africa, September 2012; 23 (8): 442-445.

30. Shi-hua F, Hong Y, Shao-nong D, Qiang L, Ya-ling Z, Ruihai Y, Yong R. Relationship between Female Menopause and Hypertension/Isolated Systolic Hypertension in Rural Districts of Hanzhong in Shaanxi Province. Acta Acad Med Sin, 2013; 35 (4): 422-426.
31. Heidari R, Sadeghi M, Talaei M, Mohammadifard N, Sarrafzadegan N. Metabolic syndrome in menopausal transitin: Isfahan Health Heart Program, a population based study. Diabetology \& Metabolic Syndrome, 2010; 2: $59-64$.

32. Deibert P, König D, Vitolins MZ, Landmann U, Frey I, Zahradnik HP et al. Effect of a weight loss intervention on anthropometric measures and metabolic risk factors in pre- versus postmenopausal women. Nutrition Journal 2007, 6:31

33. Mahajan N, Aggarwal M, Bagga A. Health Issues of menopausal women in North India. Journal of Mid-life Health, 2012; 3 (2): 84-87.

34. Carr MC. The Emergence of the Metabolic Syndrome with Menopause. J Clin Endocrinol Metab, 2003; 88 (6): 2404-2411.

35. Lee JS, Hayashi K, Mishra G, Yasui T, Kubota T, Mizunuma H. J Atheroscler Thromb, 2013; 20 (2): 161-169. 